\title{
Chinese Dynasties and Various Rulers
}

The first sages of tradition

(Fu Hsi)

(Shen Nung)

(Huang ti)

Yao

Shun

Yü

The "Three Eras" of antiquity

Hsia

Shang

Chou

Western Chou I Ith century-77I B.C.

Eastern Chou 770-256

Spring and Autumn Period 722-48I

Warring States Period 403-221

The first imperial state

Ch'in $22 \mathrm{I}-207$

(Western) Han 202-A.D. 9

Wang Mang's usurpation: the Hsin dynasty 9-23

(Eastern) Han 25-220

The Three Kingdoms 220-80

(Western) Chin 266-316

Period of Division 316-589

The Northern and Southern Dynasties 3 $17-589$ 
In the north, 386-581: (Northern) Wei 386- 534 , which divided into the Eastern and Western Wei, which were succeeded by Northern Ch'i and Northern Chou

In the south, 317-589: Eastern Chin 317-420, followed by Sung, Southern Ch'i, Liang, and Ch'en

Unification of north and south

Sui $58 \mathrm{I}-6 \mathrm{I} 8$

T'ang 618-907

T'ai-tsung 626-49

Kao-tsung 649-83

Empress Wu 684-705: the Chou dynasty 690-705

Hsuan-tsung 712-56

Su-tsung 756-62

Tai-tsung 762-79

Te-tsung 779-805

Shun-tsung 805

Hsien-tsung $805-20$

The Five Dynasties and Ten Kingdoms period of north-south division The five dynasties of the north 907-60: Later Liang, followed by Later T'ang, Later Ch'in, Later Han, and Later Chou

The ten kingdoms included in Szechuan the state of Shu and in the southeast Southern T'ang, Wu-Yueh, and Min

The Sung dynasty and the non-Han dynasties of the north the Liao dynasty of the Khitans 916-I I25

Northern Sung 960-I 127

T'ai-tsu 960-76

T'ai-tsung 976-97

Chen-tsung 997-1022

Jen-tsung 1022-63

Ying-tsung 1063-67

Shen-tsung 1067-85

Che-tsung 1085-I I00

Hui-tsung I IOO-25

Ch'in-tsung I I25-27

the Chin dynasty of the Jurchens I I I5-I 234 
Southern Sung I I 27-I 270

Kao-tsung I I 27-62

the Yuan dynasty of the Mongols $1264-1368$

The later empires

Yuan $1264-\mathrm{I} 368$

Ming I368-I 644

Ch'ing 1644-I9I I

People's Republic of China 1949- 
"This Culture of Ours"

Intellectual Transitions in T'ang and Sung China 
This page intentionally left blank 